\title{
An evaluation of 12 methods for the demonstration of penicillinase
}

\author{
T. J. LUCAS
}

From the Department of Microbiology, St. Vincent's Hospital, Darlinghurst, NSW, 2010, Australia

SUMMARY Twelve methods for the demonstration of bacterial penicillinase production by strains of Haemophilus influenzae and Staphylococcus aureus are compared, and their suitability for routine clinical laboratory use is evaluated. The acidometric agar plate method is recommended.

After the discovery of penicillinase, one of the $\beta$ lactamase group of enzymes, in 1940 (Abraham and Chain, 1940) and the demonstration of its role in the penicillin resistance of Staphylococcus aureus (Kirby, 1944) many methods began to be developed for the detection and quantitation of this enzyme. In 1962, Wolff and Hamburger published an evaluation of seven methods of determining staphylococcal penicillinase which were then current. Some of the principles being employed at that time have been adopted in more recent methods but none of the procedures described remains popular today.

Interest in demonstrating staphylococcal penicillinase in the routine clinical laboratory waned as the isolation of non-penicillinase producing staphylococci decreased. In recent years, however, the emergence of penicillinase producing strains of Haemophilus influenzae and Neisseria gonorrhoeae has given a new impetus to interest in these enzymes. A large number of new, simpler, or more rapid methods have been described in recent publications, and the present paper is an attempt to evaluate some of these methods and to compare their suitability for routine use in a clinical laboratory.

\section{Methods}

Twelve methods were used to demonstrate penicillinase production or non-production by 20 penicillin resistant and five penicillin sensitive strains of Staph. aureus and by three ampicillin resistant and six ampicillin sensitive strains of $H$. influenzae. The methods employed fal! into four categories, viz, iodometric, $\mathrm{pH}$, cephalosporin, and inhibition.

\section{IODOMETRIC METHODS}

Penicillinase hydrolyses penicillin to penicilloic acid which, in turn, reacts with iodine. The removal of

Received for publication 27 March 1979 available iodine from the system is demonstrated by the use of starch. The presence of penicillinase in a test system is shown by the decolorisation of a starch-iodine complex (Alicino, 1946; Perret, 1954). Many methods have been developed using this principle, three of which have been evaluated in this survey.

\section{Filter paper method (Perret, 1954)}

In this method the working reagent consists of a solution of penicillin $G$ containing soluble starch to which is added an iodine solution. This reagent is poured on to filter paper, and an organism is tested for penicillinase production by smearing a portion of a culture on to the paper. Penicillinase producing organisms give a zone of clearing of the starchiodine surrounding the smear of culture.

2 Iodine vapour method (Fleming and Markowsky, 1975)

This is similar to the previous method. Penicillinsoaked paper is blued with iodine vapour.

3 Slide method (Rosenblatt and Neumann, 1978)

A test organism is emulsified on a slide in a penicilliniodine solution to which a starch solution is then added. The original authors found this method effective in demonstrating pencillinase production by Staph. aureus, $\boldsymbol{H}$. influenzae, Bacteroides melaninogenicus, and $N$. gonorrhoeae.

\section{PH METHODS}

The production of penicilloic acid from penicillin lowers the $\mathrm{pH}$ of the system, and this change may be demonstrated by the use of conventional $\mathrm{pH}$ indicators.

4 Agar overlay method (Wong and Soo-Hoo, 1976) A test organism is subcultured on to an agar plate, to give a confluent lawn growth, and to this is 


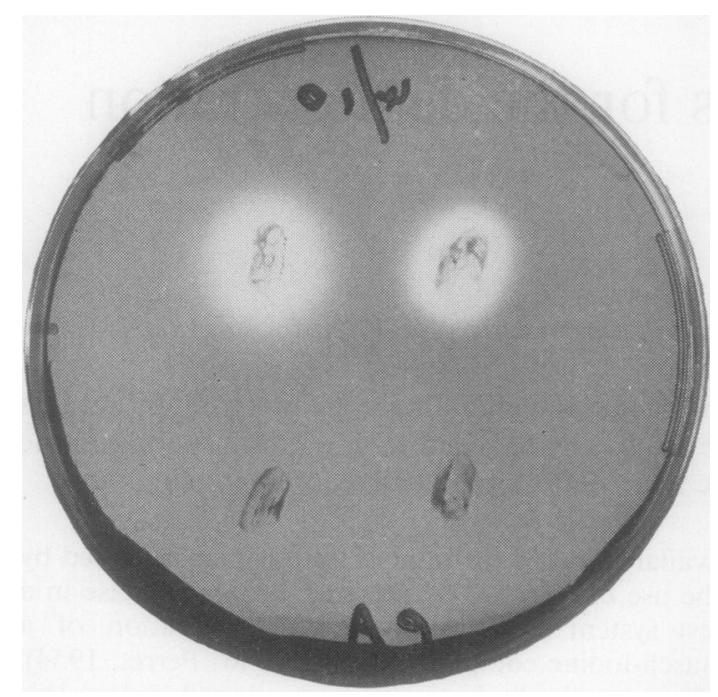

Figure Acidometric agar plate inoculated wiın Haemophilus influenzae: (top) penicillinase production; (bottom) no penicillinase production. Positive and negative tests on left have been incubated for 24 hours; tests on right have been incubated for 30 minutes.

added a $10 \mu \mathrm{g}$ methicillin sensitivity test disc. After 5 to 6 hours' incubation the plate is overlaid with an agar containing penicillin and phenol red indicator. Penicillinase production is indicated by a yellow ring which develops at the edge of the zone of inhibition around the test disc.

\section{Rapid paper strip method (Wheldon and Slack, 1978)}

This is a modification of the previous method in which a paper strip impregnated with penicillin and cresol red indicator is substituted for the agar overlay.

6 Modified one-minute tube test (Escamilla, 1976) This method is a modification of the rapid capillary tube method (Rosen et al., 1972), in which a capillary is used to pick up a penicillin and phenol red solution and is then scraped across a culture; a yellow colour develops within an hour with penicillinase producers.

In the tube test, bacteria are suspended in saline in a small test tube, and the penicillin-phenol red indicator reagent is added. Strong penicillinase producers give an instantaneous yellow colour reaction while weak reactions may take 15 to 20 minutes or, in a few cases, even longer.

7 Acidometric agar plate (Park et al., 1978) (Figure) Penicillin and phenol red are combined in a nonnutrient agar plate. The method, as described by
Park et al., was modified by increasing the final concentration of phenol red from $0.001 \%$ to $0.01 \%$ and by adding penicillin $G$ in solution rather than in powder form, thus simplifying the preparation of the plates. Organisms to be tested are smeared on to the surface of the agar and incubated at $37^{\circ} \mathrm{C}$ or at room temperature for 15-60 minutes. Penicillinase producing strains produce a brilliant yellow zone around the bacteria.

8 Commercial strip (Intralactam, Mast Laboratories Ltd, Bootle, Merseyside, UK) (Slack et al., 1977) Commercially prepared paper strips containing penicillin and bromocresol purple are moistened and smeared with test organism. A colour change from purple to yellow indicates $\beta$-lactamase production. This method is regarded as suitable for testing only Gram-negative organisms.

\section{CEPHALOSPORIN METHODS}

The chromogenic cephalosporin developed by Glaxo Research Ltd, code named 87/312, (3-(2,4 dinitrostyryl)-(6R, 7R)-7-(2-thienylacetamido)-ceph3-em-4-carboxylic acid, E isomer), has the property of showing a distinct colour change from yellow to red when hydrolysed by a wide range of $\beta$-lactamases. This characteristic has been employed in a number of methods suitable for diagnostic use. The methods evaluated share a common simple buffered solution of $87 / 312$ as the sole reagent (O'Callaghan et al., 1972; Glaxo Research Ltd, Package Insert).

\section{Plate method}

The reagent is dropped on to colonies growing on the original isolation plate. Colour develops in and around the colonies of penicillinase producing organisms.

\section{Broth method}

The reagent is added to a broth culture.

\section{Cell suspension method}

A saline suspension of the organism is tested by the addition of drops of the colour reagent.

A fourth cephalosporin method which was not evaluated is the broken cell method, in which, it is claimed, low concentrations of enzyme can be detected by testing a cell lysate.

\section{INHIBITION}

Some of the earliest methods for the demonstration of penicillinase, the Gots Test (Gots, 1945) and the Haight and Finland modification of it (Haight and Finland, 1952), use penicillin to suppress the growth of an indicator organism which is enabled to grow if penicillinase is produced by the test organism. 


\section{Inhibition}

A recent modification (Hodge et al., 1978) of this penicillin inhibition principle uses a plate seeded with a penicillin sensitive indicator organism on which is placed a penicillin disc and a radial streak of the test organism. Penicillinase production by the test organism distorts the sensitivity zone.

\section{Results}

Each of the 12 methods was tested against 20 penicillinase producing and five non-producing strains of Staph. aureus and against three penicillinase producing and six non-producing strains of $\boldsymbol{H}$. influenzae. These were compared on the basis of reliability, versatility, sensitivity, reproducibility, readability, ease and speed of performance of test, ease of preparation of reagents, relative cost, and overall suitability for routine clinical use.

\section{RELI A B I I I T Y}

In all methods tested, penicillinase producing strains of $H$. influenzae gave stronger and/or more rapid reactions than Staph. aureus strains.

Method 3 (iodometric slide) gave reactions that I found to be pale and difficult to interpret. None of the other methods gave any false-positive reactions. False-negative reactions were observed in four methods with some strains of Staph. aureus. Methods 4 (agar overlay), 11 (cephalosporin cell suspension), and 12 (inhibition) each showed one of the 20 penicillinase producing strains to be negative, and method 5 (rapid paper strip), two of 20 strains. Method 12 also gave a weak reaction with a further nine positive strains.

Method 8 (commercial strip) is recommended by the manufacturer for Gram-negative $\beta$-lactamase testing only and was shown to be unsatisfactory for testing staphylococci.

Method 9 (cephalosporin plate) also gave a poor reaction with penicillinase producing staphylococci.

\section{VERSATILITY}

With the exception of methods 3 (iodometric slide), 8 (commercial strip), and 9 (cephalosporin plate), all methods were found to be suitable for the demonstration of penicillinase production in both the species tested.

\section{SENSITIVITY}

Prolonged incubation was found to be necessary with some strains of Staph. aureus when tested by four of the methods. Method 6 (modified oneminute tube) required overnight incubation with eight strains tested, method 8 (acidometric agar plate) with six strains, and method 10 (cephalo- sporin cell suspension) required 72 hours to react with two strains. All positive reactions produced by strains of $H$. influenzae were rapid, in many cases being clearly readable in less than 1 minute.

\section{REPRODUCIBILITY}

A high degree of reproducibility was seen in all methods except method 3 (iodometric slide).

\section{READABILITY}

Methods 1 (filter paper) and 2 (iodine vapour) often gave zones that were difficult to interpret with strains of Staph. aureus. Since all cultures, penicillinase producing and non-producing, tend to give a zone of clearing after a period of several minutes, careful comparison with positive and negative controls is essential.

The readability of the $\mathrm{pH}$ methods was very good with a most distinctive colour change, in most cases, from red to yellow. The methods requiring subculture of organisms were particularly good in this respect. Methods 10 (broth) and 11 (cell suspension), using the cephalosporin, were also very distinctive but slow in changing with staphylococci. Method 12 (inhibition) gave a readily readable result in most cases. In contrast, the cephalosporin plate method (9) was good only with haemophilus cultures, the red colour being quickly and clearly visible even on chocolate (heated blood) agar.

\section{EASE AND SPEED OF PERFORMANCE}

Methods 4 (agar overlay), 5 (rapid paper strip), 10 (cephalosporin broth), and 12 (inhibition) all require subculture of the organism isolated, with consequent delay in the determination of penicillinase production.

The iodometric methods $(1,2$, and 3$)$, cephalosporin methods $(9,10$, and 11$)$, and the $\mathrm{pH}$ tube method (6) all require reagents to be prepared immediately before use, although the actual testing is quick. Methods 7 (acidometric agar plate) and 8 (commercial strip), however, are entirely prepared in advance and require only the addition of the test organism to the prepared plate or moistened strip.

The use of iodine vapour in method 2 made the actual testing rather cumbersome in comparison with other methods.

EASE OF PREPARATION AND RELATIVE COST OF REAGENTS

All methods (except 8, commercial strip) require some prior preparation of reagents, none of which is at all complex or time consuming although demanding some technical expertise (as in weighing $5 \mathrm{mg}$ of cephalosporin). Many of the stock reagents, once prepared, can be stored for some time. The most 
unstable reagent in my hands was the iodometric slide method working solution which decolorised in only a few minutes with the consequent need for a fresh solution to be prepared part way through the testing of a batch of cultures.

With the exception of the cephalosporin methods all the materials needed are inexpensive and readily available. The chromogenic cephalosporin is not commercially available.

The most expensive method must be the commercially prepared strip.

\section{Discussion}

In a clinical microbiology laboratory, apart from the epidemiological importance, the main significance of penicillinase production is directly related to the degree of urgency for the institution of specific antimicrobial therapy in a given patient. Standard antimicrobial sensitivity tests by diffusion methods require overnight incubation while automated procedures take several hours. A rapid reliable penicillinase test may make possible the early implementation of appropriate therapy.

Taking into consideration the criteria discussed above, one method stands out as meeting this need, the acidometric agar plate method (Figure). The preparation of plates is extremely simple; agar base may be prepared in quantity and stored for at least six months. When penicillin has been added to the base the poured plates are also relatively stable and have proved reliable after more than four weeks of storage at $4^{\circ} \mathrm{C}$. Since the medium is non-nutrient there is no problem of bacterial contamination or deterioration to interfere with the results. Should spontaneous hydrolysis of penicillin occur during the storage of prepared plates, this will be shown by a colour change of the indicator. In use, a prepared plate may be taken from the refrigerator and directly inoculated with test organisms. As many as 14 cultures could be tested on a single $90 \mathrm{~mm}$ petri dish. Positive results are normally apparent within 15-30 minutes, but, unlike in some other methods, there is neither fading of positive results nor falsepositive reactions on prolonged incubation; the colour zone tends to enlarge with time but, provided that inocula are not too close together, both positive and negative results remain clearly readable after 48 hours. After the completion of this study the acidometric agar plate method was adopted in this laboratory for the routine testing of all $\boldsymbol{H}$. influenzae isolates. At the time of writing, a further 141 strains have been examined, 136 of which were ampicillin sensitive and negative for penicillinase production by this method, and five which were ampicillin resistant and penicillinase producing.
In every way the acidometric agar plate method appears ideal for the demonstration of bacterial penicillinase in the clinical microbiology laboratory.

I am grateful to Glaxo Research Laboratories for providing samples of the chromogenic cephalosporin.

\section{References}

Abraham, E. P., and Chain, E. (1940). An enzyme from bacteria able to destroy penicillin (Letter). Nature, $146,837$.

Alicino, J. F. (1946). Iodometric method for the assay of penicillin preparations. Industrial and Engineering Chemistry (Analytical Edition), 18, 619-620.

Escamilla, J. (1976). Susceptibility of Haemophilus influenzae to ampicillin as determined by use of a modified, one minute beta-lactamase test. Antimicrobial Agents and Chemotherapy, 9, 196-198.

Fleming, P. C., and Markowsky, B. (1975). The rapid detection, incidence and significance of ampicillin resistant strains of $H$. influenzae. 15th Interscience Conference on Antimicrobial Agents and Chemotherapy, Abstract 387.

Gots, J. S. (1945). Production of extracellular penicillininactivating substances associated with penicillin resistance in Staphylococcus aureus. Proceedings of the Society of Experimental Biology and Medicine, 60, 165-168.

Haight, T. H., and Finland, M. (1952). Modified Gots test for penicillinase production. American Journal of Clinical Pathology, 22, 806-808.

Hodge, W., Ciak, J., and Tramont, E. C. (1978). Simple method for detection of penicillinase-producing Neisseria gonorrhoeae. Journal of Clinical Microbiology, 7, 102-103.

Kirby, W. M. M. (1944). Extraction of a highly potent penicillin inactivator from penicillin resistant staphylococci. Science, 99, 452-453.

O'Callaghan, C. H., Morris, A., Kirby, S. M., and Shingler, A. H. (1972). Novel method for detection of $\beta$-Lactamases by using a chromogenic cephalosporin substrate. Antimicrobial Agents and Chemotherapy, 1, 283-288.

Park, C. H., Lopez, J. S., and Cook, C. B. (1978). Acidometric agar plate method for ampicillin susceptibility testing of Haemophilus influenzae. Antimicrobial Agents and Chemotherapy, 13, 318-320.

Perret, C. J. (1954). Iodometric assay of penicillinase. Nature, 174, 1012-1013.

Rosen, I. G., Jacobson, J., and Rudderman, R. (1972). Rapid capillary tube method for detecting penicillin resistance in Staphylococcus aureus. Applied Microbiology, 23, 649-650.

Rosenblatt, J. E., and Neumann, A. M. (1978). A rapid slide test for penicillinase. American Journal of Clinical Pathology, 69, 351-354.

Slack, M. P. E., Wheldon, D. B., and Turk, D. C. (1977). A rapid test for beta-lactamase production by Haemophilus influenzae. Lancet, 2, 906.

Wheldon, D. B., and Slack, M. P. E. (1978). A rapid 
paper-strip method for the detection of penicillinase production by penicillin resistant strains of Staphylococcus aureus. Journal of Clinical Pathology, 31, 388-389.

Wolff, D. A., and Hamburger, M. (1962). Evaluation of some currently used methods for determining staphylococcal penicillinase. Journal of Laboratory and Clinical Medicine, 59, 469-480.

Wong, K. W., and Soo-Hoo, T. S. (1976). A rapid, simple agar overlay method for the detection of penicillinase-producing Staphylococcus aureus in the clinical bacteriology laboratory. Japanese Journal of Microbiology, 20, 153-154.

Requests for reprints to: T. J. Lucas, Microbiology Department, St Vincent's Hospital, Darlinghurst, NSW 2010, Australia.

\section{The September 1979 Issue}

\section{THE SEPTEMBER 1979 ISSUE CONTAINS THE FOLLOWING PAPERS}

Herpesviruses MORAG C. TIMBURY AND ELIZABETH EDMOND

The morphology of emphysema, chronic bronchitis, and bronchiectasis: Definition, nomenclature, and classification B. E. HEARD, V. KHATCHATOUROV, H. OTTO, N. V. PUTOV, AND L. SOBIN

A clinical view of analytical goals in clinical biochemistry ANNE E. BARRETT, S. J. CAMERON, C. G. FRASER, L. A. PENBERTHY, AND KAREN L. SHAND

Serum immunoreactive trypsin concentrations in infectious and non-infectious illnesses and in juvenile diabetes D. R. GAMBLE, ANNE MOFFATT, AND VINCENT MARKS

Serum $\gamma$-glutamyltransferase isoenzymes in extrahepatic biliary obstruction P. R. WENHAM, C. P. PRICE, AND H. G. SAMMONS

Plasma blood group changes in gastrointestinal tract carcinoma PH. ROUGER, D. RIVEAU, CH. SALMON, AND J. LOYGUE

T-cell nature of leukaemic cells in a case of Sézary's syndrome with 'null-cell' features L. LAURIOLA, P. MUSIANI, A. CARBONE, M. BARTOLINI, P. CIANCIULLI, AND M. PIANTELLI

An immunohistochemical study of the distribution of carcinembryonic antigen in epithelial tumours of the ovary J. HEALD, C. H. BUCKLEY, AND H. FOX

Transfusion requirements of adolescents with severe haemophilia A A. ARONSTAM, D. S. MCLELlAN, AND P. TURK
Use of the ultracentrifuge vertical rotor in the detection of rubella-specific IgM on a sucrose density gradient P. LUTON AND G. L. RIDGWAY

Biotypes of Klebsiella pneumoniae (sensu lato) and Enterobacter aerogenes characterised by differential substrate metabolism: application of the technique J. G. BARR AND G. M. HOGG

A survey of the sensitivity of fresh clinical isolates to cefuroxime and other antibiotics $L$. 0 . POTASCHMACHER, C. H. DASH, K. A. JEFFERSON, AND MARGARET R. K. KENNEDY

Endocarditis due to Micrococcus sedentarius incertae sedis D. C. OLD AND G. P. MCNEILL

Meningitis caused by Pseudomonas paucimobilis v. HAJiroussou, B. HOLMes, J. Bullas AND C. A. PINNING

Use and interpretation of Schlichter's test on Haemophilus influenzae: Relation of in vitro to in vivo results for cefamandole E. YOURASSOWSKY, M. P. VAN DER LINDEN, AND E. SCHOUTENS

\section{Technical method}

Countercurrent immunoelectrophoresis: improved detection of pneumococcal capsular antigens in sputum by incorporation of a carboxylated derivative of phenyl boronic acid M. C. KELSEY AND C. S. REED

Book reviews

The Association of Clinical Pathologists: 103rd Scientific Meeting

Copies are still available and may be obtained from the PUBLISHING MANAGER, BRITISH MEDICAL ASSOCIATION, TAVISTOCK SQUARE, LONDON WC1H 9JR, price $£ 3 \cdot 00$, including postage 